\title{
Ultrasound assisted remote functionalization of non-activated carbon atoms: efficient in situ formation of tetrahydrofurans by sonolysis of bromohydrins with (diacetoxyiodo)benzene $/ \mathrm{I}_{2}$
}

\author{
Saul C. P. Costa, M. J. S. Miranda Moreno, M. Luisa Sá e Melo* and André S. Campos Neves \\ Centro de Estudos Farmacêuticos, Laboratório de Química Farmacêutica, Faculdade de Farmácia, Universidade de Coimbra, \\ 3000 Coimbra, Portugal
}

Received 17 August 1999; accepted 28 September 1999

\begin{abstract}
Ultrasonic irradiation of bromohydrins in the presence of (diacetoxyiodo)benzene and $\mathrm{I}_{2}$ generates alkoxyl radicals which lead in situ to intramolecular hydrogen abstraction on the C-19 non-activated carbon atoms in steroids producing tetrahydrofurans selectively in very good yields. Photolysis was less effective in promoting such conversions. (C) 1999 Elsevier Science Ltd. All rights reserved.
\end{abstract}

Keywords: steroids; tetrahydrofurans; halohydrins; sonochemistry.

Remote functionalization of non-activated carbon atoms has found particular relevance in steroid chemistry. ${ }^{1}$ As part of our studies dealing with the synthesis of potential aromatase inhibitors, namely 19-hydroxyandrostane derivatives, ${ }^{2}$ to be employed therapeutically on estrogen-dependent diseases, we focused our attention on oxidative cyclization at C-19. Functionalization of this angular methyl group is commonly achieved through the preparation of tetrahydrofurans as precursors of 19-hydroxysteroids ${ }^{1}$ and, consequently, the generation of alkoxyl radicals suitably positioned to allow intramolecular hydrogen abstraction is required (Scheme 1).

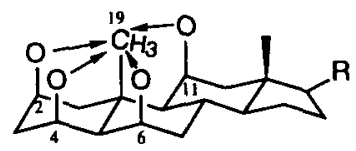

Scheme 1.

Most of the methods that have been developed to achieve this remote oxidation involve the addition of hypohalous acids to $\Delta^{5}$-steroids 1 to introduce the hydroxyl group at C-6 (Scheme 2). Subsequent oxidation of the halohydrins 2 at C-19 take place through the formation of the corresponding $6 \beta$ alkoxyl radicals that allows intramolecular hydrogen abstraction at C-19 leading to the cyclic-ethers

* Corresponding author. Fax: 35139 827030; e-mail: samelo@ci.uc.pt 
3. To generate alkoxyl radicals from alcohols, photolytic decomposition of heavy metals derivatives and iodine have been traditionally employed. ${ }^{1,3}$

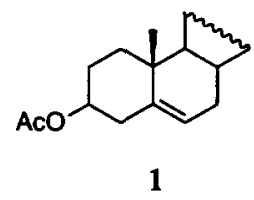

1

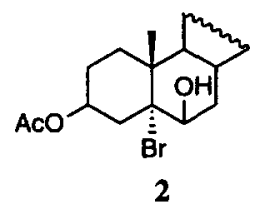

2

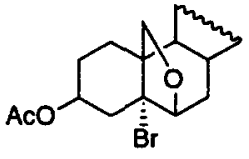

3

Scheme 2.

More recently, in situ photolysis of alcohols with visible light in the presence of (diacetoxyiodo)benzene (DIB) and iodine was reported as a higher yielding methodology. ${ }^{4}$ However, when 1,2bromohydrins were submitted in a first trial of this reaction (with $\mathrm{DIB} / \mathrm{I}_{2}$ ) under the conditions reported for alcohols, the corresponding 6 6,19-tetrahydrofurans were obtained in very low yields. Such results led us to use sonolysis as an alternative to photolysis. Indeed, acoustic cavitation generated within a liquid phase by power ultrasound ( 20 to $100 \mathrm{KHz}$ ) has been successfully used to promote chemical reactivity and the synthetic applications of this activation process cover a wide range of chemical transformations. ${ }^{5}$ Nevertheless, sonochemical oxidation of $\mathrm{C}-\mathrm{H}$ bonds, especially non-activated ones, has not been extensively reported. The creation of a new $\mathrm{C}-\mathrm{O}$ bond with $\mathrm{LTA} / \mathrm{I}_{2}$ under sonochemical conditions was the single example we found in the literature. ${ }^{6}$

Our group has been performing research in this field of growing interest, directed towards the study of homogenous and heterogeneous systems. ${ }^{7}$ In a previous communication we reported the preliminary results obtained when ultrasonic irradiation was applied to improve the preparation of tetrahydrofurans through the hypoiodite reaction, using the $\mathrm{DIB} / \mathrm{I}_{2}$ system. ${ }^{7 \mathrm{a}}$ The study we present here was performed while seeking to optimize the sonolyses of bromohydrins in the presence of $\mathrm{DIB} / \mathrm{I}_{2}$ towards formation of 63,19-tetrahydrofurans in situ. The evaluation of some important reaction parameters, such as temperature, reaction time and molar ratio of $\mathrm{DIB} / \mathrm{I}_{2}$ per mol of substrate and their effects on the conversion rates and on the formation of by-products, has been undertaken.

Substrates 4-6 (Scheme 3) have been previously synthesized by reaction of the corresponding commercially available $\Delta^{5}$-steroids with $10 \% \mathrm{HClO}_{4}$ and $\mathrm{N}$-bromosuccinimide ${ }^{8}$ and fully characterized by ${ }^{1} \mathrm{H}$ and ${ }^{13} \mathrm{C}$ NMR. ${ }^{9}$ The 20 -oxopregn-5-ene-3 $\beta, 21$-di-yl diacetate required to prepare the bromohydrin 7 , may be easily obtained from the also commercially available 20 -oxopregn-5-ene-3 $\beta$-yl acetate, as previously described by us. ${ }^{10}$
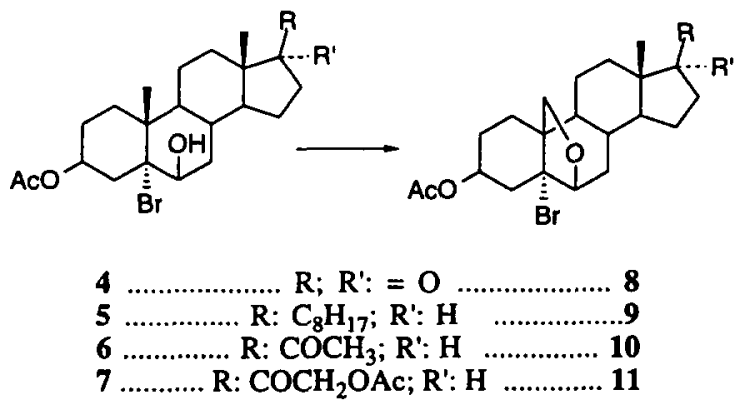

Scheme 3.

As a first approach we carried out a set of experiments on substrate 4 at various temperatures $(35,40$, 45 and $50^{\circ} \mathrm{C}$ ), using an ultrasonic cleaning bath $(35 \mathrm{KHz}$ ) with circulating water. The best result was observed at the selected temperature of $45^{\circ} \mathrm{C}$. This implies that the cavitation efficiency is higher under these reaction conditions, consequently allowing an improvement in the chemical reactivity. Further 
Table 1

Reaction of bromohydrins with $\mathrm{DIB} / \mathrm{I}_{2}$

\begin{tabular}{|c|c|c|c|c|}
\hline Entry & Substrate & $\overline{\mathrm{DIB} / \mathrm{I}_{2}}$ & Irradiation ${ }^{b)}$ & Product (\%)c) \\
\hline I & 4 & $1.1 / 1.0$ & light & $8(43)$ \\
\hline II & 4 & $1.4 / 1.2$ & light & $8(77)$ \\
\hline III & 4 & $1.1 / 1.0$ & ())) & $8(86)$ \\
\hline IV & 4 & $1.4 / 1.2$ & ))) & $8(92)$ \\
\hline $\mathrm{v}$ & 5 & $1.4 / 1.2$ & ))) & $9(90)$ \\
\hline VI & 6 & $1.4 / 1.2$ & ))) & $10(90)$ \\
\hline VII & 7 & $1.4 / 1.2$ & )) & $11(99)$ \\
\hline
\end{tabular}

a) substrate: $0.10-0.12 \mathrm{mmol}$; solvent mixture: cyclohexane/benzene (10:1); reaction temperature: $45^{\circ} \mathrm{C}$.

b) Light: $200 \mathrm{~W}$ (2 lamps of 100W tungsten filaments); ))): ultrasonic bath Bandelin Sonorex Super RK 510H,

$225-450 \mathrm{~W}, 35 \mathrm{KHz}$; reaction time: 50 minutes. ${ }^{\mathrm{c})}$ Quantified and identified by ${ }^{1} \mathrm{H} \mathrm{nmr}$ (isolated crude product)

increase of the temperature led to a larger consumption of substrate 4 , however a higher amount of by-products, namely the corresponding $5 \beta, 6 \beta$-epoxide was produced, while the target product 8 was obtained in a lower yield. Furthermore, $50 \mathrm{~min}$ was established as a suitable reaction time to accomplish this conversion under sonochemical conditions. In fact, we have performed the experiments using $0.10-0.12 \mathrm{mmol}$ of substrate and complete conversions were found after that irradiation time. The use of extended ultrasonic periods gave an intractable mixture of products.

By changing the molar ratio of $\mathrm{DIB} / \mathrm{I}_{2}$ per mol of substrate to $1.4 / 1.2$ an additional optimization was attained. Interestingly, at this stoichiometry the conversion rate enhancement achieved for photolytic reactions (Table 1, Entries I and II), was found to be considerably higher than that of the reaction performed under ultrasonic conditions (Table 1, Entries III and IV).

The combination of all optimized parameters led to a synergic effect on the sonochemical remote oxidation on C-19 for substrate 4 (Table 1, Entry IV). With the aim of illustrating the versatility and synthetic potential of this ultrasonic approach for the hypoiodite reaction performed with $\mathrm{DIB} / \mathrm{I}_{2}$, these studies were extended to the analogous derivatives of cholestane 5 and of 20-oxo- and 21-acetoxy20-oxopregnanes 6 and 7, which have not been investigated before under such reaction conditions. As depicted in Table 1 (Entries V-VII) the corresponding 63,19-tetrahydrofuranic steroids 9-11 were readily accessible by the same sonolytic procedure. The reactions proceeded smoothly under the mild conditions used. It should also be emphasized that a 40-fold scale-up of a sonicated reaction conducted for substrate 4 was successful (70\% yield, after crystallization). All the compounds were fully characterized by ${ }^{1} \mathrm{H}$ and ${ }^{13} \mathrm{C}$ NMR. ${ }^{11}$ In closing, this study has demonstrated that ultrasonic irradiation is a valuable alternative to light since it provides better yields, easier work-up of the products and good selectivity. The results attained are in agreement with the proposition that radical processes are favoured by sonication. The easy availability of ultrasonic cleaning baths as well as its operational simplicity render this procedure extremely attractive and practical. Besides, the application to the synthesis of potential precursors of highly valuable 19-hydroxyandrostane derivatives as well as cholestane and pregnane analogues, allow us to believe that this methodology will find general acceptance in organic synthesis.

\section{Acknowledgements}

We thank the former Junta Nacional de Investigação Científica (JNICT) and Fundação para a Ciência e Tecnologia (FCT), PRAXIS XXI and PRODEP programs for their past and present financial contributions and the award of fellowships. 


\section{References}

1. Heusler, K.; Kalvoda, J. In Organic Reactions in Steroid Chemistry; Fried, J.; Edwards, J. A., Eds.; Van Norstrand Reinhold: New York, 1972; Vol. II, pp. 237-264.

2. Pereira da Costa, S. C. Ph.D. Thesis, University of Coimbra, 1999.

3. Heusler, K.; Kalvoda, J. Angew. Chem., Int. Ed. Engl. 1964, 3, 525-538.

4. Armas, P.; Concepción, J. I.; Francisco, C. G.; Hernández, R.; Salazar, J. A.; Suárez, E. J. Chem. Soc., Perkin Trans. I $1989,405-411$.

5. (a) Mason, T. J. Chem. Soc. Rev. 1997, 26, 443-451. (b) Mason, T. J.; Luche, J. L. In Chemistry Under Extreme or NonClassical Conditions; Van Eldik, R.; Hubbard, C. D., Eds.; Ultrasound as a new tool for synthetic chemists. John Wiley \& Sons and Spektrum Akademisher Verlag, 1997; pp. 317-380. (c) Luche, J. L. Synthetic Organic Sonochemistry; Plenum Press: New York and London, 1998.

6. Konoike, T.; Takanashi, K.; Araki, Y.; Horibe, I. J. Org. Chem. 1997, 62, 960-966.

7. (a) Sá e Melo, M. L.; Moreno, M. J. S. M.; da Costa, S. P.; Salvador, J. A. R.; Campos Neves, A. S. Ultrasonics Sonochemistry 1994, I, S37-S40. (b) Moreno, M. J. S. M.; Sá e Melo, M. L.; Campos Neves, A. S. Tetrahedron Lett. 1993, 34, 353-356. (c) Salvador, J. A. R.; Sá e Melo, M. L.; Campos Neves, A. S. Tetrahedron Lett. 1993, 34, 357-360; Salvador, J. A. R.; Sá e Melo, M. L.; Campos Neves, A. S. ibid 1993, 34, 361-362.

8. Grenville, V.; Patel, D. K.; Petrow, V.; Stuart-Webb, I. A.; Williamson, D. M. J. Chem. Soc. 1957, III, 4105-4111.

9. (a) Substrate 4: $\delta_{\mathrm{H}}(500 \mathrm{MHz}) 0.86\left(3 \mathrm{H}, \mathrm{s}, 18-\mathrm{H}_{3}\right), 1.42\left(3 \mathrm{H}, \mathrm{s}, 19-\mathrm{H}_{3}\right), 2.01\left(3 \mathrm{H}, \mathrm{s}, \mathrm{CH}_{3} \mathrm{COO}\right), 4.27(1 \mathrm{H}, \mathrm{s}, 6 \alpha-\mathrm{H}), 5.51$ $(1 \mathrm{H}, \mathrm{m}, 3 \alpha-\mathrm{H}) ; \delta_{\mathrm{C}}(125 \mathrm{MHz}) 72.2(\mathrm{C}-3), 74.6(\mathrm{C}-6), 88.4(\mathrm{C}-5), 170.4\left(\mathrm{OCOCH}_{3}\right), 220.8(\mathrm{C}-17)$. (b) Substrate 5: $\delta_{\mathrm{H}}$ $(500 \mathrm{MHz}) 0.67\left(3 \mathrm{H}, \mathrm{s}, 18-\mathrm{H}_{3}\right), 0.85,0.86,0.87,1.32\left(3 \mathrm{H}, \mathrm{s}, 19-\mathrm{H}_{3}\right), 2.03\left(3 \mathrm{H}, \mathrm{s}, \mathrm{CH}_{3} \mathrm{COO}\right), 4.17(1 \mathrm{H}, \mathrm{s}, 6 \alpha-\mathrm{H}), 5.46$ $(1 \mathrm{H}, \mathrm{m}, 3 \alpha-\mathrm{H}) ; \delta_{\mathrm{C}}(125 \mathrm{MHz}) 72.2(\mathrm{C}-3), 75.6(\mathrm{C}-6), 86.8(\mathrm{C}-5), 170.5\left(\mathrm{OCOCH}_{3}\right)$. (c) Substrate 6: $\delta_{\mathrm{H}}(500 \mathrm{MHz}) 0.63$ $\left(3 \mathrm{H}, \mathrm{s}, 18-\mathrm{H}_{3}\right), 1.33\left(3 \mathrm{H}, \mathrm{s}, 19-\mathrm{H}_{3}\right), 2.03\left(3 \mathrm{H}, \mathrm{s}, \mathrm{CH}_{3} \mathrm{COO}\right), 2.12\left(3 \mathrm{H}, \mathrm{s}, 21-\mathrm{H}_{3}\right), 4.19(1 \mathrm{H}, \mathrm{s}, 6 \alpha-\mathrm{H}), 5.47(1 \mathrm{H}, \mathrm{m}, 3 \alpha-\mathrm{H})$; $\delta_{\mathrm{C}}(125 \mathrm{MHz}) 55.9,63.6,72.2(\mathrm{C}-3), 75.4(\mathrm{C}-6), 86.9(\mathrm{C}-5), 170.5\left(\mathrm{OCOCH}_{3}\right), 209.8(\mathrm{C}-20)$. (d) Spectroscopic data for substrate 7 was consistent with the lit.: Veleiro, A. S.; Nevado, M. V.; Monteserín, M. C.; Burton, G. Steroids 1995, 60, 268-271.

10. Moreno, M. J. S. M.; Martins, R. M. L. M.; Sá e Melo, M. L.; Campos Neves, A. S. Chem. Lett. 1997, 529-530.

11. Product 8: $\delta_{\mathrm{H}}(500 \mathrm{MHz}) 0.91\left(3 \mathrm{H}, \mathrm{s}, 18-\mathrm{H}_{3}\right), 2.03\left(3 \mathrm{H}, \mathrm{s}, \mathrm{CH}_{3} \mathrm{COO}\right), 3.75(1 \mathrm{H}, \mathrm{d}, 19-\mathrm{Ha}, J=8.5 \mathrm{~Hz}), 3.97(1 \mathrm{H}, \mathrm{d}, 19$ $\mathrm{H}-\mathrm{b}, J=8.5 \mathrm{~Hz}), 4.12(1 \mathrm{H}, \mathrm{d}, 6 \alpha-\mathrm{H}, J=4.2 \mathrm{~Hz}), 5.19(1 \mathrm{H}, \mathrm{m}, 3 \alpha-\mathrm{H}) ; \delta_{\mathrm{C}}(125 \mathrm{MHz}) 14.2,21.3,21.4,21.9,23.3,26.9,31.4$, $31.9,33.1,35.8,41.3,46.1,48.3,48.8,49.4,67.6(\mathrm{C}-19), 69.8(\mathrm{C}-3), 74.2(\mathrm{C}-5), 82.0(\mathrm{C}-6), 170.3\left(\mathrm{OCOCH}_{3}\right), 220.8$ (C-17). Product 9: $\delta_{\mathrm{H}}(500 \mathrm{MHz}) 0.69\left(3 \mathrm{H}, \mathrm{s}, 18-\mathrm{H}_{3}\right), 0.85,0.86,0.87,2.02\left(3 \mathrm{H}, \mathrm{s}, \mathrm{CH}_{3} \mathrm{COO}\right), 3.74(1 \mathrm{H}, \mathrm{d}, 19-\mathrm{Ha}, J=8.5$ $\mathrm{Hz}), 3.92(1 \mathrm{H}, \mathrm{d}, 19 \mathrm{H}-\mathrm{b}, J=8.5 \mathrm{~Hz}), 4.05(1 \mathrm{H}, \mathrm{d}, 6 \alpha-\mathrm{H}, J=4.5 \mathrm{~Hz}), 5.19(1 \mathrm{H}, \mathrm{m}, 3 \alpha-\mathrm{H}) ; \delta_{\mathrm{C}}(125 \mathrm{MHz}) 12.4,18.6,21.3$, $22.5,22.6,22.8,23.3,23.4,23.7,26.8,28.0,28.2,32.8,33.2,35.7,36.1,39.5,39.7,41.3,43.1,45.8,48.6,54.3,56.0,67.5$ (C-3), $69.9(\mathrm{C}-19), 74.5(\mathrm{C}-5), 82.3(\mathrm{C}-6), 170.2\left(\mathrm{OCOCH}_{3}\right)$. Product 10: $\delta_{\mathrm{H}}(500 \mathrm{MHz}) 0.65\left(3 \mathrm{H}, \mathrm{s}, 18-\mathrm{H}_{3}\right), 2.03(3 \mathrm{H}$, s, $\left.\mathrm{CH}_{3} \mathrm{COO}\right), 2.11\left(3 \mathrm{H}, \mathrm{s}, 21-\mathrm{H}_{3}\right), 3.72(1 \mathrm{H}, \mathrm{d}, 19-\mathrm{Ha}, J=8.5 \mathrm{~Hz}), 3.93(1 \mathrm{H}, \mathrm{d}, 19 \mathrm{H}-\mathrm{b}, J=8.5 \mathrm{~Hz}), 4.07(1 \mathrm{H}, \mathrm{d}, 6 \alpha-\mathrm{H}$, $J=4.2 \mathrm{~Hz}), 5.19(1 \mathrm{H}, \mathrm{m}, 3 \alpha-\mathrm{H}) ; \delta_{\mathrm{C}}(125 \mathrm{MHz}) 13.8,21.3,22.6,22.8,23.3,23.6,26.8,31.4,32.7,33.3,38.7,41.2,44.6$,

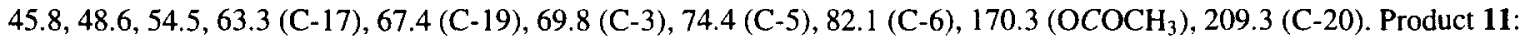
spectroscopic data fully agree with the published data. ${ }^{9 \mathrm{~d}}$ 